Meta

Journal des traducteurs

Translators' Journal

\title{
Bilinguisme et anglicisation au Québec : que nous dit la presse ?
}

\section{Cécile Planchon}

Volume 60, numéro 2, août 2015

$60^{\mathrm{e}}$ anniversaire. Les horizons de la traduction : retour vers le futur

$60^{\text {th }}$ Anniversary. Translation's Horizons: Back to the Future

60mo aniversario. Los horizontes de la traducción: regreso al futuro

URI : https://id.erudit.org/iderudit/1032914ar

DOI : https://doi.org/10.7202/1032914ar

Aller au sommaire du numéro

Éditeur(s)

Les Presses de l’Université de Montréal

ISSN

0026-0452 (imprimé)

1492-1421 (numérique)

Découvrir la revue

Citer ce document

Planchon, C. (2015). Bilinguisme et anglicisation au Québec : que nous dit la presse ? Meta, 60(2), 363-363. https://doi.org/10.7202/1032914ar d'utilisation que vous pouvez consulter en ligne.

https://apropos.erudit.org/fr/usagers/politique-dutilisation/ 


\title{
Bilinguisme et anglicisation au Québec: que nous dit la presse?
}

\author{
Cécile Planchon \\ Université d'Ottawa, Ottawa, Canada \\ cplan059@uottawa.ca
}

En tant que Canadiens francophones, les Québécois sont naturellement exposés à un environnement bilingue constant. L'influence de la langue officielle majoritaire l'anglais - sur leur langue maternelle ne peut donc pas être ignorée. Vu la politique linguistique officiellement en vigueur au Québec, la presse écrite imprimée devrait être très attentive à la protection de la langue française. Cependant, elle n'échappe pas au problème d'anglicisation et les traces laissées par le contact perpétuel avec l'anglais sont visibles dans l'utilisation fréquente de termes anglais ou anglicisés à l'écrit (Théoret 1991; Martel et al. 2001; Davis 2011; Chaput 2013).

Cette présentation se propose d'étudier l'influence du contexte culturel et linguistique des lectorats sur le degré d'anglicisation de la presse québécoise. En analysant trois journaux destinés à trois communautés différentes, à savoir Le Soleil, La Presse et Le Droit, respectivement tirés à Québec, Montréal et Gatineau, je cherche à savoir si la fréquence d'utilisation des anglicismes est liée à la présence plus ou moins dominante de la langue anglaise dans la vie quotidienne du lectorat cible. Utilisant une liste de plus de 500 anglicismes répertoriés dans Le Multidictionnaire, cette étude se concentre sur les emprunts lexicaux intégraux et hybrides, c'est-à-dire ceux présentant une graphie anglaise non ou peu adaptée (shopping, lobby, focusser). Basés sur un corpus regroupant une année entière de publications (plus de 86000 articles), les résultats préliminaires semblent montrer que plus l'environnement est bilingue, plus la langue s'anglicise, car le journal de l'Outaouais comptabilise à peu près $20 \%$ d'anglicismes de plus que La Presse et $25 \%$ de plus que Le Soleil, ce qui confirmerait ainsi mon hypothèse de départ.

Cécile Planchon est doctorante en traductologie à l'École de traduction et d'interprétation de la Faculté des arts de l'Université d'Ottawa, diplômée en traduction trilingue, en études chinoises et en études anglophones. Traductrice de formation, elle s'intéresse principalement aux contacts entre les langues, notamment aux emprunts linguistiques, à leur impact à long et court terme ainsi qu'aux rapports qu'entretiennent les utilisateurs de la langue avec les politiques linguistiques en place et aux raisons qui les poussent à recourir à l'emprunt. Elle est également professeure à temps partiel (grammaire, stylistique, traduction françaises) et elle a codirigé un ouvrage collectif portant sur les rapports franco-chinois «Miroirs croisés: Chine-France $-\mathrm{xVII}{ }^{\mathrm{e}}-\mathrm{XXI}{ }^{\mathrm{e}}$ siècle», publié aux Éditions Champion. Elle a publié son premier article dans Belas Infiéis en début d'année. 